\title{
Diffuse idiopathic skeletal hyperostosis (DISH): an unusual cause of airway obstruction
}

\author{
Andrew Wesley Hoey, Keli Dusu, Simon Gane
}

Department of Otolaryngology, Royal National Throat Nose and Ear Hospital, London, UK

\section{Correspondence to} Andrew Wesley Hoey, andrew.hoey@nhs.net

Accepted 25 February 2017

\section{DESCRIPTION}

Acute airway obstruction is a common ENT emergency with a wide range of aetiologies. The most common causes are infection, malignancy and foreign bodies, but more unusual causes should be considered. $^{1}$

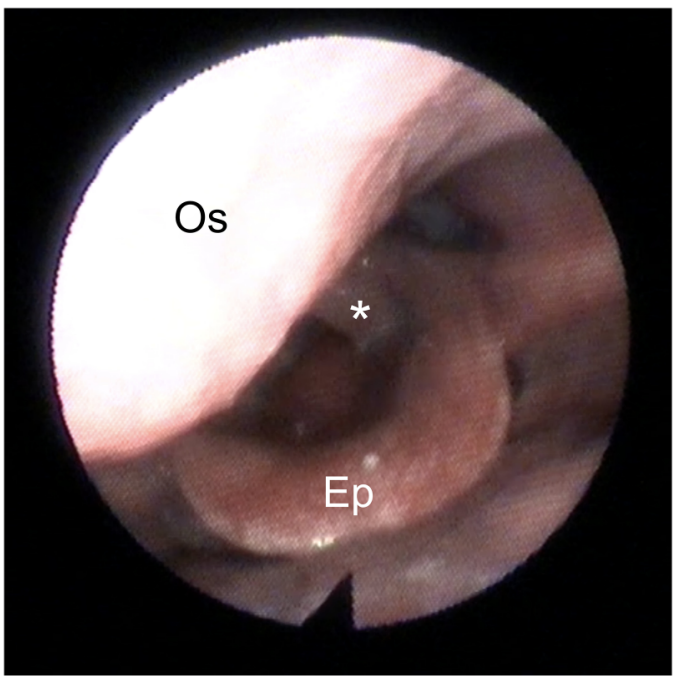

Figure 1 Flexible nasendoscopy demonstrating a large posterior pharyngeal mass protruding into the airway resulting in narrowing of the glottic inlet as well as supraglottic oedema (Os, osteophyte compressing the posterior pharyngeal wall; Ep, epiglottis; *vocal fold demonstrating glottic oedema).
A 77-year old gentleman presented to the emergency department with worsening difficulty in breathing for 3 months since undergoing spinal surgery for multilevel cervical myelopathy. He of stertor, cough, dysphagia and intermittent apnoea. He was otherwise systemically well with no clinical signs of sepsis. Flexible nasendoscopy revealed a large posterior pharyngeal wall mass obscuring the glottis (figure 1).

CT of the neck revealed a large confluence of osteophyte formation from C2 to C5, protruding into and distorting the posterior pharyngeal wall and larynx, resulting in narrowing of the glottic inlet (figure 2). The patient underwent an emergency tracheostomy in order to secure the airway. During the procedure, bone cutters were required to create the tracheal window due to severe calcification of the trachea. Once stabilised, he was transferred to a neurosurgical centre for surgical osteophytectomy.

A diagnosis of diffuse idiopathic skeletal hyperostosis (DISH) was made. DISH primarily affects elderly men and results in ossification of ligaments and tendons as well as parts of the upper aerodigestive tract. Characteristically, ossification of the anterior longitudinal ligament is seen, resulting in the formation of intervertebral osteophytes. ${ }^{2}$ Although asymptomatic in most cases, patients may have symptoms such as dysphagia and dysphonia, and very rarely airway obstruction. ${ }^{3}$

Acute airway obstruction is rare in this condition, but securing a safe airway follows the same protocol and assessment as for the other causes. Early
To cite: Hoey AW, Dusu K, Gane S. BMJ Case Rep Published online: [please include Day Month Year] doi:10.1136/bcr-2017219635

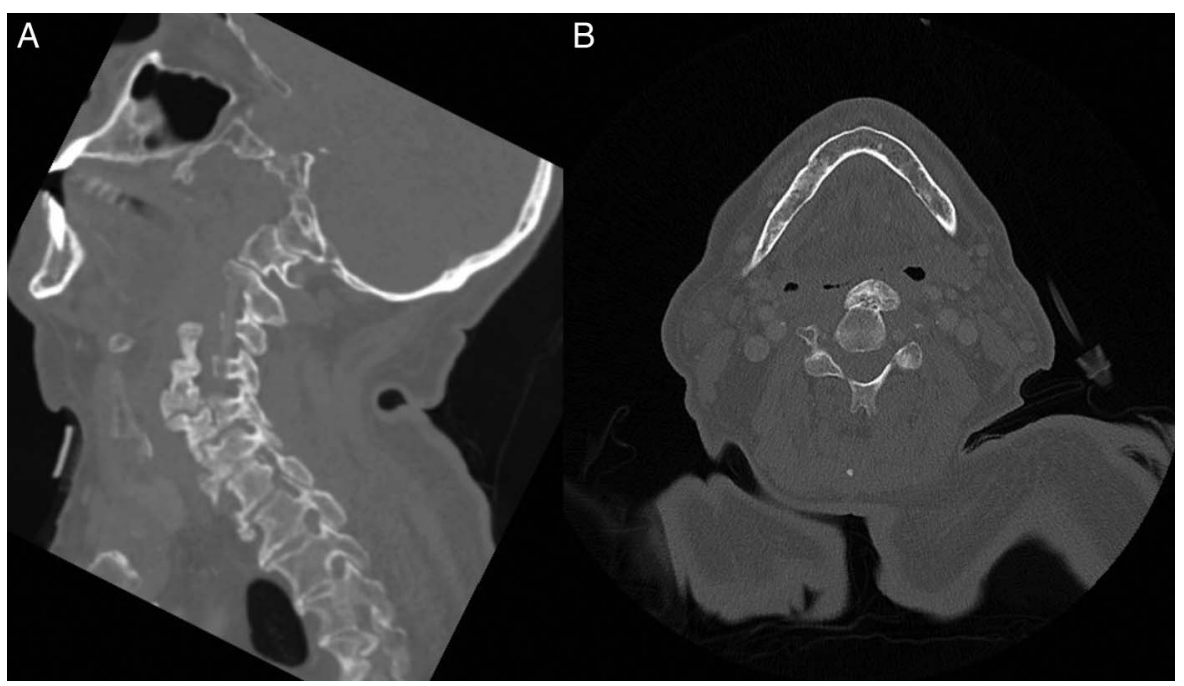

Figure 2 CT scan of the neck (A, sagittal view; B, axial view) demonstrating a large cervical osteophyte compressing the posterior pharyngeal wall resulting in narrowing of the airway. 
assessment and clinical observation by an experienced airway clinician will guide intervention.

\section{Learning points}

- There are a wide range of aetiologies of acute airway compromise; these tend to be infection, malignancy and foreign bodies.

- More unusual causes for airway compromise must always be considered when the aetiology is not immediately obvious.

- Urgent assessment by an airway-trained clinician should be sought as soon as possible all cases of airway obstruction.
Contributors AWH reviewed the literature and prepared the manuscript. KD provided critical review and images. SG revised and supervised the manuscript.

Competing interests None declared.

Patient consent Obtained.

Provenance and peer review Not commissioned; externally peer reviewed.

\section{REFERENCES}

1 Pfleger A, Eber E. Assessment and causes of stridor. Paediatr Respir Rev 2016;18:64-72.

2 Resnick D, Shaul SR, Robins JM. Diffuse idiopathic skeletal hyperostosis (DISH): Forestier's disease with extraspinal manifestations. Radiology 1975;115:513-24

3 Verlaan JJ, Boswijk PFE, de Ru JA, et al. Diffuse idiopathic skeletal hyperostosis of the cervical spine: an underestimated cause of dysphagia and airway obstruction. Spine J 2011;11:1058-67.

Copyright 2017 BMJ Publishing Group. All rights reserved. For permission to reuse any of this content visit http://group.bmj.com/group/rights-licensing/permissions.

BMJ Case Report Fellows may re-use this article for personal use and teaching without any further permission.

Become a Fellow of BMJ Case Reports today and you can:

- Submit as many cases as you like

- Enjoy fast sympathetic peer review and rapid publication of accepted articles

- Access all the published articles

- Re-use any of the published material for personal use and teaching without further permission

For information on Institutional Fellowships contact consortiasales@bmjgroup.com

Visit casereports.bmj.com for more articles like this and to become a Fellow 